\title{
USING MULTIMEDIA CASE STORIES OF EXEMPLARY TEACHING FOR FACULTY DEVELOPMENT
}

\author{
Tasha J. Souza, Humboldt State University \\ Tom Carey, Higher Education Quality Council of Ontario \\ Flora McMartin, Broad-based Knowledge, LLC \\ Roberta Ambrosino, UT Health Science Center at San Antonio \\ Joe Grimes, California Polytechnic State University
}

Faculty are more likely to embrace the possibility of change when they see change modeled by their colleagues. Through a multimedia case story, faculty can share in the experience of using an innovative teaching strategy and the process of implementing it. Integrating multimedia case stories into our work with faculty can help us meet diverse faculty needs and encourage more faculty to embrace pedagogical change. Such stories

We thank the conscientious attention of the reviewers and editors of this volume. We are pleased to acknowledge the stellar contributions of the MERLOT ELIXR program staff-Season Eckardt, Lou Zweier, Joel Bennett, and Cynthia Desrochers-and the ongoing support of MERLOT's executive director, Gerry Hanley, to our success with using multimedia case stories in faculty development. We also thank the ELIXR faculty development fellows, Kathy Ross, Kiren Dosanjh Zucker, Roberta Ambrosino, and Joe Grimes, for their active engagement with the case stories. We appreciate the thirty faculty development centers that created ELIXR case stories, providing us with engaging and valuable resources to enhance teaching and learning. The MERLOT ELIXR program was supported in part by a grant from the Department of Education, Fund for the Improvement of Post-Secondary Education. 
can help faculty to realize that they too can overcome pedagogical challenges and institutional constraints in order to better meet the learning needs of students.

Centers for teaching and learning need to provide professional development opportunities focused on innovative pedagogies that meet twenty-first-century faculty members' "unique professional development and support needs, especially in the area of teaching and learning" (Diaz et al., 2009, p. 54). Universities today must consider changes in faculty development programs in the same way that they consider new teaching and learning approaches for their students. Vrasidas and Glass (2004) contend that "the demands of world and family life for teachers [coupled with the rise in part-time faculty] ... underline the need for professional development activities that can be delivered anytime, anywhere" (p. 4). Diaz and others (2009) suggest that successful faculty development programs "incorporate flexible scheduling and various delivery options" (p. 54), "provide access to online resources" (p. 54), and include delivery in diverse formats (face-to-face, blended, online, and self-paced).

Freidus and Hlubinka (2002) note in a study of early users that sharing faculty experiences with innovative teaching and learning approaches through digital storytelling using case stories and supporting documents enhances and accelerates the adoption of exemplary teaching practices. Multimedia case stories, as developed for the MERLOT ELIXR (2009) project, combine faculty storytelling with course artifacts and interactive resources to illustrate exemplary teaching practices. ELIXR offers an online repository of multimedia case stories and resources on innovative pedagogy. These stories highlight different disciplinary approaches to pedagogical innovation, relevant teaching contexts, unique design or assessment methods, and student-centered teaching approaches. Viewing a changed classroom strategy through a multimedia case story lens provides an example of how faculty implement new pedagogical strategies and redesign courses to promote significant learning (Fink, 2003). To see such examples, readers are encouraged to scan one or more case stories on the ELIXR website (MERLOT ELIXR, 2009) or from the list in the WikiPODia article on Digital Case Stories for Faculty Development (POD Network, 2009).

\section{Multimedia Case Stories Defined}

The use of cases has a long history in various educational contexts (Ellet, 2007; Grossman, 1992; Kim et al., 2006). Cases reveal interpersonal complexity in context with all its connections to other aspects of 
classroom life (Anson, Jolliffe, \& Shapiro, 1995). Cases are useful in preparing preservice teachers for the classroom (Anson et al., 1995). A case-based approach to teacher development encourages thoughtfulness among teachers (Boyer, 1990; Abell, Bryan, \& Anderson, 1998) by capturing the wisdom of practice (Bransford, Brown, \& Cocking, 1999). "Because cases are rich retellings of real classroom events, they encourage teachers to move beyond the 'idea' of a teaching issue by seeing it played out in a particular context" (Anson et al., 1995, p. 26). Hutchings (1992) contends that cases are a powerful tool for faculty development and offer a productive way for faculty to improve teaching and learning. Research suggests that cases can improve faculty learning by addressing context and relevance (Lowenthal, 2008).

Building on the success of cases, multimedia case stories combine elements of both case studies and digital storytelling. Multimedia case stories are a relatively new genre with two distinct attributes. First, they are real or realistic stories about teaching-not lessons, presentations, or even reflections (although a good story may contain all or some of these elements) presented through a digital medium. The power of stories to improve learning is well documented (Abrahamson, 1998; Connelly \& Clandinin, 1994; McDury \& Alterio, 2003). The key characteristic of a good story is that it draws in the audience members to imaginatively relate to the story. A good story about teaching helps other teachers experience what the storyteller has done and feel what the storyteller has felt. Second, these stories are also cases organized for learning. In the ELIXR multimedia case stories described here, the learners are teachers in higher education, and so storytellers reflect on questions their faculty colleagues might ask as they consider a new pedagogical approach.

Each ELIXR multimedia case story is unique, reflecting both a particular teaching method and the unique qualities that all teachers bring to their classes. However, most contain the following elements, either as individual components or integrated in sections customized to the story and the faculty storyteller's perspective:

- Overview. Before diving into a story, most viewers start with the overview, a short video thumbnail of the case story that previews the content and affective dimensions of the case in order to help viewers decide whether they want to explore the case further.

- Story narrative. The story narrative outlines, in video and text, why the practice was adopted, the resulting changes, how students responded to these changes in teaching, and evidence that these changes made a difference in student learning. Although the case is 
created by a team that includes experts in faculty development and digital media, the authorship of the story is personalized to reinforce the notion that the faculty member is the author-storyteller. Critical to the story are the successes and difficulties the authorstoryteller encountered.

- Personal reflection. The author's personal reflection, in video and text, provides the viewer with a more personal account of the changes the innovator experienced in teaching and learning.

- More detail. The detail on this story provides resources that will help others understand the course more fully in order to use the methods demonstrated in the story. Example resources include course syllabi, assignments, links to outside resources, and assessment data such as actual examples of student work. A potential video element would be students at work demonstrating the implementation.

- Faculty development resources. The faculty development resources section, if there is one, contains resources and tools for faculty developers to use with the case stories.

\section{Benefits of Multimedia Case Stories in Faculty Development}

The following benefits are ones that we specifically targeted in our design and use of multimedia case stories for faculty development.

\section{See New Strategies in Action}

Multimedia case stories present new ways of demonstrating particular teaching and learning innovations (Mitchem et al., 2009). Instead of simply talking about goals for the first day of class, for example, faculty can see a first-day-of-class goal described by the faculty member and the process of achieving that goal (Desrochers \& Grimes, 2007).

\section{Provide Discipline-Specific Examples}

A recent study in the United Kingdom noted that most faculty, when considering approaches to teaching and learning, primarily seek and respect advice and guidance given by colleagues in their own discipline. Faculty are, at best, broadly tolerant of a generic approach; they would rather be provided with stepping-stones to link pedagogical strategies with their disciplinary context (Supporting New Academic Staff Project Team, 2006). For example, faculty in the sciences may prefer examples from the sciences about integrating active learning strategies, and faculty 
in the humanities may prefer to learn about the same topic from their own disciplinary colleagues. "Without contextualizing and making things relevant, attracting faculty and hence helping support the transfer of what faculty learn to their own classroom to improve their teaching is futile" (Lowenthal, 2008, p. 351).

\section{Demonstrate Both the Product and Process of Innovations in Teaching}

Reciprocal classroom visits are a way for faculty developers to promote dialogue among faculty while ensuring the learners' perspective is a focal point (Helling \& Kuhlmann, 1988; Hutchings, 1996), but what is most visible in these visits is the product of change. Multimedia case stories provide a similar experience, with the added benefit of showing both the product and process of innovations in teaching. Recent research documents the effectiveness of process-oriented case studies in fostering a learning-centered perspective in faculty workshops. "Process-oriented information refers to the principled (why) and strategic (how) information that experts use when solving problems ... adding process-oriented information to worked examples can enhance transfer performance" (Hoogveld, Paas, \& Jochems, 2005, p. 287).

\section{Target Evolving Faculty Concerns with Just-in-Time Learning}

Multimedia case stories provide a rich resource for faculty to use to follow up on workshop programs as their questions about a particular method evolve. The concerns-based adoption model (CBAM) provides a framework for typical questions teachers ask over time in considering a change in teaching methods (Hord, Rutherford, Huling-Austin, \& Hall, 1987). Initial ELIXR case story work used CBAM to target evolving faculty concerns with just-in-time learning, weaving stories around a CBAM question sequence that might arise for another instructor considering use of a new teaching approach. Questions covered reasons for the approach, approaches to using it, impact on students and the course, challenges and rewards, and assessment.

\section{Extend Access to Faculty Development Opportunities}

Typical faculty development programs offer one-time workshops or institutes as ways to attract participants to faculty development efforts. While such programs are convenient for some, research suggests that lack of time 
and competing priorities are two major obstacles to faculty participation in such programs (Stevens et al., 2005). Using multimedia case stories in combination with more traditional methods can extend access to faculty development opportunities and more efficiently reach a broader range of faculty (DiPietro et al., 2009). Because multimedia case stories and their related resources are available online, faculty can explore the stories when the time is convenient, and repeatedly if necessary. Faculty who might be reluctant to ask for help can use such online resources anonymously (DiPietro et al., 2009). While the multimedia case stories from the ELIXR project were developed with the intention of faculty development events as the primary access method, the stories are also used by individual faculty by means of websites to support teaching. For example, the Pedagogy in Action website (SERC, 2009) uses multimedia case stories as illustrations within a rich set of online resources on particular teaching methods like concept tests and just-in-time teaching. Online multimedia case stories are especially useful for underserved faculty such as adjuncts who cannot easily take advantage of traditional faculty development programs and consultations.

\section{Using Multimedia Case Stories in Faculty Development}

Faculty development professionals have used multimedia case stories in face-to-face workshops, online learning opportunities, faculty learning communities (FLCs), and consultations. The stories are stand-alone tools or supplements to any faculty development activity. The multimedia case stories offer the flexibility needed for different faculty development needs. The faculty developer must, of course, review the potential case story before use to be sure that it will provide the desired outcomes and ensure the appropriate pedagogical placement of the story in the larger program design. Faculty developers have incorporated multimedia case stories into face-to-face workshops in the following ways:

- Asking participants to preview cases as preparation for a workshop

- Showcasing story elements to demonstrate a point or lead into an exercise

- Forming groups to review and reflect on the case story

- Providing links to cases in workshop materials as suggested followup resources 
- Sending new faculty links to case stories relevant to new faculty orientation

- Sending cases to faculty as orientation to new instructional initiatives

Similar approaches can be used with FLCs and consultations with faculty. Faculty can preview cases prior to a meeting, view cases during a meeting or consultation, or review cases after a meeting or consultation as a follow-up resource.

Face-to-face workshops and programs are often expensive and fail to attract a large number of faculty members (Lowenthal, 2008). Case stories used for online faculty development offer a less expensive alternative. Such self-paced online learning opportunities "can help address attracting faculty to attend workshops by eliminating issues of time and place" (Lowenthal, 2008, p. 351). Given the increasing popularity of online learning and teaching (Shea, Sherer, \& Kristensen, 2001; Vrasidas \& Glass, 2004), the need for online faculty development may increase, especially in times of declining resources.

\section{Evaluating the Use and Usability of Case Stories in Faculty Development}

The ELIXR program team is evaluating the outcomes of the project as a whole while examining three areas in particular: use in face-to-face faculty development, use in online faculty development, and the usability of the cases for faculty developers. Evaluators collect data along three dimensions: participation, faculty learning, and impact on teaching and learning. The ELIXR project, begun in 2006, has focused primarily on developing the case stories. Since 2008 , case stories have been available for use online, so given the early stage of the project, the focus to date is on faculty satisfaction and learning, not student learning.

Through the ELIXR website, faculty developers have access to survey instruments to evaluate the effectiveness of face-to-face or online workshops. Additional survey instruments measure knowledge prior to the workshop or allow participants to report what they have learned and how they have applied it to their teaching. Collection of these data is ongoing, and the information provided in this chapter illustrates the types of responses received to date. Preliminary analysis indicates that faculty and faculty developers find the case stories meaningful, appreciate the variety of disciplines and topics represented, and believe the stories would be most useful for less experienced instructors. 


\section{Face-to-Face Faculty Development Evaluation Data}

Evaluation conducted by the faculty developers who used case story resources in face-to-face workshops and FLCs reported faculty reactions as well as data regarding actual and anticipated changes to teaching practice. The small numbers of participants in the workshops make it inappropriate to report anything beyond descriptive statistics. The following information from several of these faculty developers provides an overview of their evaluation efforts.

California State University, San Luis Obispo used the Universal Design for Learning in Information Systems (UDL) case story (Beckman, 2009) as part of a UDL meeting of FLCs five times for two hours each time. Over the course of these sessions, each faculty member reviewed and discussed material on the fundamentals of UDL and planned the transformation of his or her courses by receiving suggestions from others in the learning community. After completing the activities and prior to the final meeting, members reviewed the ELIXR case story on how to improve learning using UDL principles. Members reviewed the case at this stage so that their initial designs would not be unduly influenced by the case story. The case story provided confirmation of the value of UDL, illustrated a variety of UDL techniques (for example, small group discussions, guided notes, use of online multimedia), and included sample assessment techniques that reinforced the importance of assessment and evaluation.

FLC participants confirmed two main benefits of case story use: seeing UDL happen is better than just talking about or reading about how it should happen, and interdisciplinary discussions of the case stories allow different insights to emerge. All FLC participants felt the case story was valuable for them, and all followed through by implementing UDL in revised courses.

University of Texas Health Science Center took a different approach and used the First Day of Class case story (Desrochers \& Grimes, 2007) in two face-to-face workshops with participants from various disciplines, different teaching environments, and varying years of experience. Seasoned faculty led the workshops and related case stories to their own experiences with discussions of their own questions, tips, and reflections, resulting in rich interactions around first-day instructional strategies, especially about framing course content and motivating students. Both the workshop facilitators and the participants rated the workshops favorably. The facilitators felt that the story format of the ELIXR resources promoted a story-sharing atmosphere, which led to the faculty openly 
identifying and comparing their differences in disciplines and teaching environments. The workshop evaluations indicated that 60 percent of the thirty participants found that the case stories contributed to their learning, which compared favorably with the other aspects of the workshop (for example, 80 percent for discussions with peers and 47 percent for handouts).

California State University, Fullerton used the First Day of Class (Desrochers and Grimes, 2007) case story as well but in a ninety-minute session as part of a two-day orientation for new faculty. Approximately fifty faculty attended, viewing the First Day of Class case story at the end of the two days. The case story revived the fatigued group, who seemed to appreciate the ability to work on their own classes. The session used many methods and resources, including a handout of the most common goals for the first day of class, a case story video showing two instructors dealing with first-day classes, a large group discussion about individual goals, a writing activity for participants to select upcoming first-day goals, a pair-share of those goals, and completion of a first-day planning template with references to the relevant disciplinary case stories. Participants chose methods to achieve goals and shared first-day plans in small groups. The overall average rating of the value of the workshop was 4.2 on a scale of 1 to 6 , with the case story rated at 4.0 and discussion with colleagues at 4.7. Such scores suggest that discussion of the case stories can be more valuable than simply viewing the case stories. Many favorable comments were written about the use of the case stories, and 75 percent of the respondents reported that they would likely use what they had learned in the workshop in their own first day of class.

Looking more closely at the kind of behavioral change that Fullerton's data suggest, Humboldt State University conducted a focus group with new faculty a week after they attended a similar first-day-of-class workshop, where the value of the workshop case stories was rated as a 3.7 on a 1 to 5 scale. The inquiry focused on the kinds of changes participants made to their first day of class that they attributed to the workshop and in particular to the case stories. Twelve participants attended the meeting, and all reported that they. made changes to their classes as a result of attending the workshop and viewing the case stories.

Each evaluation effort shows that the methods used were specific to the context of the campus. The results were useful to the faculty developers in refining their workshops, a primary goal for the program's evaluation efforts. 


\section{Online Professional Development Data}

A secondary use of the ELIXR case stories is through individual faculty accessing online resources such as a discipline-specific teaching portal. The Science Education Resource Center (SERC) at Carleton College studied the ELIXR case stories to assess the value and utility of integrating the First Day of Class and Just in Time Teaching stories into their existing website, Teach the Earth, which makes pedagogical modules available for use by for geosciences faculty. Faculty reported that the case stories contributed to their knowledge about the topic or affirmed their existing knowledge. One participant wrote, "I have spent 20 -something years walking into the first day of class, right, every semester, all different kinds of settings. And, what I have learned on the fly through shear [sic] years of experience is captured here in this website. So, in a way, it's completély reinforcing of knowledge I have acquired the hard way" (SERC, 2009, p. 7). Two study participants noted, when reflecting on the use of the videos, "By actually demonstrating the ideas, the videos provided concrete examples," and, "It would be difficult to conceptualize the techniques without the videos" (SERC, 2009, pp. 8-9).

The faculty who participated in the SERC study found that multimedia case stories demonstrating techniques, using real faculty in real classroom settings, are effective complements to the textual descriptions in the existing modules. Findings from this initial study indicate that faculty exploring the case studies in an online environment learn from the ELIXR stories because they relate to the genuineness of the stories and see how to apply the techniques in their own classroom settings.

\section{Usability Data of Case Stories for Faculty Development}

At the ELIXR program level, two evaluation questions regarding usability and potential for dissemination are of prime importance. To better understand faculty developers' views of the cases and determine methods for disseminating them, the ELIXR evaluators conducted an observational user study of the case stories with faculty developers who attended the 2009 MERLOT International Conference. In this study, we asked participants to view a case story for fifteen to twenty minutes, after which they responded to a survey or participated in a one-on-one structured interview. Participants tended to be experienced instructors in addition to being faculty developers. Study participants reported that the case stories were engaging, content well organized, and video segments compelling. 
We observed that most participants viewed the entire case story, even though the study did not require them to do so.

In their role as instructors, around 60 percent of the participants reported that the case story piqued their interest in trying out a new teaching strategy or in integrating it into a future course or class. About 35 percent reported that the cases added to what they already knew about the story topic, which suggests that experts chose to view the stories to test their accuracy and validity, while people new to the topic viewed them to learn more about the topic. In their role as faculty developers, 70 percent of respondents reported that they would share the case stories with other instructors or administrators on their campus. In a follow-up survey conducted in November 2009, respondents reported that they had not changed their teaching practices because of viewing the case story. This finding must be viewed with caution, however, because many of the participants were experienced teachers already expert in the topic area of the case story they reviewed. In their faculty developer roles, over half of the respondents reported they had recommended the case stories to faculty, faculty development colleagues, or administrators on their campus. However, none of the respondents reported using them in formal faculty development programs. This could be the result of the timing of the survey (given that their fall programming may have already been in place at the time they first viewed the case stories) or might suggest that exposure to a resource one time may not be enough to encourage immediate use.

These findings are generally encouraging but also reveal the challenges of adopting innovative faculty development resources. Successful adoption requires more than simply making people aware of a resource. In particular, faculty developers must have the time and support to examine the case story resources in some depth and redesign programs to integrate them. The consensus from the faculty developers using the ELIXR case stories is that faculty participating in their programs benefited from use of the cases.

\section{Conclusion}

Our experiences and observations, along with the emerging evaluation data, convince us of the value of multimedia case stories as a new genre for faculty to share knowledge about exemplary teaching. The reports in this chapter represent initial efforts to understand, apply, and evaluate multimedia case stories in our programs for faculty. We encourage readers to make use of ELIXR resources, available for use at no charge, and to contribute to the knowledge exchange about their use and value. 


\section{REFERENCES}

Abell, S. K., Bryan, L. A., \& Anderson, M. (1998). Investigating pre-service elementary science teacher reflective thinking using integrated media case-based instruction in elementary science teacher preparation. Science Education, 82(4), 491-509.

Abrahamson, C. E. (1998). Storytelling as a pedagogical tool in higher education. Education, 118(3), 440-451.

Anson, C. M., Jolliffe, D. A., \& Shapiro, N. (1995). Stories to teach by: Using narrative cases in TA and faculty development. Writing Program Administration, 19(1), 24-37.

Beckman, P. (2009). Universal design for learning in information systems case story. Retrieved from http://pachyderm.cdl.edu/elixr-stories/udl-information-systems/

Boyer, E. L. (1990). Scholarship reconsidered: Priorities of the professoriate. Princeton, NJ: Carnegie Foundation for the Advancement of Teaching.

Bransford, J. D., Brown, A. L., \& Cocking, R. R. (1999). How people learn: Brain, mind, experience, and school. Washington, DC: National Academy Press.

Connelly, F. M., \& Clandinin, D. J. (1994). Telling teaching stories. Teacher Education Quarterly, 21(1), 145-158.

Desrochers, C., \& Grimes, J. (2007). Making your 1st class session really first class. Retrieved from http://pachyderm.cdl.edu/elixr-stories/1stday-slo/

Diaz, V., Garrett, P. B., Kinley, E. R., Moore, J. F., Schwartz, C. M., \& Kohrman, P. (2009). Faculty development for the 21st century. EDUCAUSE Review, 44(3), 46-55.

DiPietro, M., Ambrose, S. A., Bridges, M., Fay, A., Lovett, M. C., \& Norman, M. K. (2009). Defeating the developer's dilemma: An online tool for individual consultations. In L. B. Nilson \& J. E. Miller (Eds.), To improve the academy: Vol. 27. Resources for faculty, instructional, and organizational development (pp. 183-198). San Francisco: Jossey-Bass.

Ellet, W. (2007). Case study handbook: How to read, discuss, and write persuasively about cases. Boston: Harvard Business School Press.

Fink, L. D. (2003). Creating significant learning experiences: An integrated approach to designing college courses. San Francisco: Jossey-Bass.

Freidus, N., \& Hlubinka, M. (2002). Digital storytelling for reflective practice in communities of learners. ACM SIGGROUP Bulletin, 23(2), 24-26.

Grossman, P. L. (1992). Teaching and learning with cases: Unanswered questions. In J. Shuman (Ed.), Case methods in teacher education (pp. 227-239). New York: Teachers College Press.

Helling, B., \& Kuhlmann, D. (1988). The faculty visitor program: Helping teachers see themselves. In K. G. Lewis \& J.T.P. Lunde (Eds.), 
Face to face: A sourcebook of individual consultation techniques for faculty instructional developers (pp. 135-148). Stillwater, OK: New Forums Press. Hoogveld, A.W.M., Paas, F., \& Jochems, W.M.G. (2005). Training higher education teachers for instructional design of competency-based education: Product-oriented versus process-oriented worked examples. Teaching and Teacher Education, 21(3), 287-297.

Hord, S. M., Rutherford, W. L., Huling-Austin, L., \& Hall, G. (1987). Taking charge of change. Alexandria, VA: Association for Supervision and Curriculum Development.

Hutchings, P. (1992). Using cases to talk about teaching. AAHE Bulletin, 44(8), 6-8.

Hutchings, P. (1996). Making teaching community property. Washington, DC: American Association for Higher Education.

Kim, S., Phillips, W. R., Pinsky, L., Brock, D., Phillips, K., \& Keary, J. (2006). A conceptual framework for developing teaching cases: A review and synthesis of the literature across disciplines. Medical Education, 40(9), 867-876.

Lowenthal, P. R. (2008). Online faculty development and storytelling: An unlikely solution to improving teacher quality. MERLOT Journal of Online Teaching and Learning, 4(3), 349-356.

McDrury, J., \& Alterio, M. (2003). Learning through storytelling in higher education: Using reflection and experience to improve learning. London: Kogan Page.

MERLOT ELIXR. (2009). Welcome to MERLOT ELIXR. Retrieved from http://elixr.merlot.org

Mitchem, K., Koury, K., Fitzgerald, G., Hollingsead, C., Miller, K., Tsai, H. H., et al. (2009). The effects of instructional implementation on learning with interactive multimedia case-based instruction. Teacher Education and Special Education: The Journal of the Teacher Education Division of the Council for Exceptional Children, 32, 297-318.

POD Network. (2009). WikiPODia. Retrieved from http://sites.google.com/site/ podnetwork/

SERC. (2009). The Science Education Research Center. Retrieved from http://serc.carleton.edu/sp/library/conceptests/index.html and http://serc.carleton.edu/sp/library/justintime/index.html

Shea, T. P., Sherer, P. D., \& Kristensen, E. W. (2001). Harnessing the potential of online faculty development: Challenges and opportunities. In D. Lieberman \& C. M. Wehlburg (Eds.), To improve the academy: Vol. 20. Resources for faculty, instructional, and organizational development (pp. 162-179). San Francisco: Jossey-Bass/Anker. 
Stevens, E., Dunlap, J., Bates, B., Lowenthal, P., Wray, M., \& Switzer, T. (2005). Faculty development attitudes and motivators. Paper presented at the annual meeting of the Northern Rocky Mountain Educational Research Association, Jackson, WY.

Supporting New Academic Staff Project Team. (2006). The generic meets the discipline. Retrieved from www.medev.ac.uk/docs/generic_meets_the _discipline_update.pdf

Vrasidas, C., \& Glass, G. V. (2004). Online professional development for teachers. Greenwich, CT: Information Age. 